\title{
Stage IIA1 Cervical Cancer AJCC v8
}

National Cancer Institute

\section{Source}

National Cancer Institute. Stage IIA1 Cervical Cancer A/CC v8. NCI Thesaurus. Code C139745.

Stage IIA1 includes: T2a1, Any N, M0. T2a1: Cervical carcinoma invading beyond the uterus but not to the pelvic wall or to lower third of vagina without parametrial invasion. Clinically visible lesion $4.0 \mathrm{~cm}$ or less in greatest dimension. M0: No distant metastasis. (AJCC 8th Ed.) 